\title{
AS DIREITAS NA DEMOCRACIA PORTUGUESA Origens, Percursos, Mudanças e Novos Desafios [Riccardo Marchi, 2016, Alfragide, Texto]
}

\author{
Mariana Carmo Duarte \\ Instituto Universitário de Lisboa (ISCTE-IUL), Lisboa, Portugal
}

Um pouco por toda a Europa, e desde o despoletar da atual crise económico-financeira, temos assistido a uma radicalização política e, consequentemente, a uma polarização em torno da clivagem esquerda/direita, que, historicamente, tem orientado a vida política. Concomitantemente, tem ressurgido o debate teórico e ideológico em torno desta clivagem, tendo não só em conta a sua relevância na explicação do passado, mas também a sua validade na análise do presente e prospeção daquilo que será a política no futuro. Em Portugal, um dos países mais afetados pela presente conjuntura económica e financeira, esta dicotomia parece não estar ultrapassada. A política nacional nos últimos quatro anos tem sido vincadamente marcada pelo governo de coligação de direita, PSD (Partido Social Democrata) CDS-PP (CDS - Partido Popular) (2011-2015) e, mais do que nunca, no léxico dos portugueses parece ter sido reforçado, por oposição a "esquerda", o termo "direita". Dado este contexto, afigura-se pertinente a leitura do livro As Direitas na Democracia Portuguesa. Origens, Percursos, Mudanças e Novos Desafios, coordenado por Riccardo Marchi e publicado em janeiro do presente ano.

A obra aqui em análise é interessante para todos aqueles que, muito embora não tenham um background em Ciência Política ou áreas adjacentes, queiram compreender os principais traços característicos, bem como a evolução histórica, sociológica, cultural, programática e eleitoral da direita portuguesa. Beneficiando dos contributos de vários autores, este livro é uma compilação de 11 análises e reflexões sobre as várias dimensões integrantes desta família política, cujo resultado final perfaz um todo coerente. Deste modo, são aqui analisados os partidos políticos de direita, o surgimento e a evolução, quer de uma cultura, quer de uma opinião pública de direita, e a relação da mesma família política com o estado, o mercado e a igreja. Cirurgicamente, e em pouco mais de 400 páginas, são fornecidas as ferramentas adequadas à interpretação da direita portuguesa, sendo focadas as suas origens, percursos, mutações e novos desafios.

Em termos partidários, a direita na III República portuguesa tem sido, primordialmente, marcada pelos dois partidos com assento parlamentar: o PSD e o CDS-PP. Neste livro, são claramente expostas não só as suas semelhanças e convergências programáticas, mas também as suas singularidades. Ora, o PSD é aqui apresentado, tanto por Ana Rita Ferreira, como por José Pedro Zúquete, como um partido que, aquando da sua formação, em maio de 1974, sob o nome de PPD (Partido Popular Democrático), se regia pelos fundamentos da social-democracia. Todavia, a formação, no final dos anos 70, da coligação AD (Aliança Democrática) traria mudanças irreversíveis na linha ideológica do partido. 
Em coligação com o CDS e o PPM (Partido Popular Monárquico), o PSD abandonou, progressivamente, a sua vertente ideológica em prol de uma política cada vez mais pragmática. Esta tendência foi, de acordo com Ferreira, reforçada pelo "triunfo do cavaquismo" (p. 105). Para Manuel Monteiro, foi o fracasso em empurrar o PS (Partido Socialista) para os braços do PCP (Partido Comunista Português) que levou o PSD a colocar os seus planos doutrinários em segundo lugar e a abraçar o pragmatismo. Embora, até à década de 1990, se tivesse tentado conservar alguns princípios basilares da social-democracia, já então era possível encontrar no partido aspetos distintivos do liberalismo, a nível económico, e do conservadorismo, a nível cultural. O início da década de 2000 marca, por influência do CDS-PP, um claro corte com os resquícios de social-democracia ainda existentes no partido e um reforço das tendências liberais e conservadoras.

Na opinião de Zúquete, para além de todas estas mutações, o partido está envolto num quadro genético que se tem mantido e tem guiado as suas dinâmicas e práticas. Entre outros traços, compõem o seu quadro genético, desde a sua fundação, as seguintes características: a autonomia e independência da sociedade civil face ao estado, o pragmatismo, o populismo e o portuguesismo. De acordo com Zúquete, se o reformismo foi, durante anos, também considerado um traço genético característico deste partido, este parece ter-se desvanecido com a liderança de Pedro Passos Coelho. Outro fator relevante na análise daquele que é o quadro genético do partido é o pai fundador do mesmo: Francisco Sá Carneiro. Num partido onde a coerência ideológica não é grande, cabe à figura do líder a união das várias fações. Neste sentido, são certeiras as palavras de Zúquete ao classificar Sá Carneiro como "o Noé desta arca" (p. 170).

O CDS-PP, partido que no período após o 25 de Abril e até ao início da década de 1990 assumia o centrismo como a sua ideologia, é, consensualmente, aqui definido e analisado tendo em conta a sua plasticidade. Quer Ana Rita Ferreira, quer Patrícia Silva e Carlos Jalali, quer, ainda, Manuel Monteiro corroboram esta ideia nas suas diversas análises sobre o partido. Nascido em julho de 1974, sob o nome de CDS (Centro Democrático Social), este partido cedo revelou ser uma "amálgama ideológica" (p. 100), como o descreve Ferreira. Tendo passado por um curto período de "esquerdização" (p. 100), aquando das eleições de 1976, viria a afirmar, até ao início da década de 1990, a democracia-cristã, o liberalismo económico e o conservadorismo cultural como os seus ideais.

Passados os conturbados anos de indefinição ideológica, e como nos retrata Manuel Monteiro, presidente do CDS à data, o partido afirma-se, em março de 1992, como sendo de direita. Consequentemente, em janeiro de 1993, o seu nome é mudado para Partido Popular, alterando-se a sua sigla para CDS-PP. No seu capítulo, Monteiro aborda a questão europeia como tópico central a ter em conta no estudo deste partido durante grande parte da década de 1990. Retratando um período no qual foi interveniente, descreve as atitudes do partido contra a ideia de federalismo europeu, a oposição face ao tratado de Maastricht e a defesa de uma Europa das nações onde é mantida a soberania de cada estado. O início do novo milénio marca, por seu turno, um atenuar do liberalismo e um acentuar do conservadorismo, que até então tinham andado a par e de mãos dadas. 
Numa análise complementar, Patrícia Silva e Carlos Jalali analisam estas mudanças programáticas do CDS-PP tendo em conta três ângulos: o desempenho eleitoral, a mudança de líder e a relação do partido com o PSD. De acordo com estes autores, o partido apresenta-se como sendo, de entre os que têm representação parlamentar, o que indicia maior volatilidade programática. É nas situações em que o desempenho eleitoral é avaliado negativamente que se verifica, por um lado, uma maior alteração programática e, por outro lado, uma mudança das lideranças. Adicionalmente, parte da mudança programática do partido parece ser consequência da sua necessidade de se posicionar estrategicamente face ao PSD.

A evolução e a mutação programáticas dos dois partidos que compõem a direita portuguesa parlamentar é, em larga medida, um processo conjunto e de influência mútua. Como argumenta Ana Rita Ferreira, desde 1974 que os dois partidos se encontram, indiscutivelmente, mais à direita e, ideologicamente, muito mais próximos. No entender de Patrícia Silva e Carlos Jalali, esta proximidade foi reforçada pelo CDS-PP durante os anos de liderança de Paulo Portas com o objetivo de aceder ao governo. Porém, se, entre o liberalismo económico e o conservadorismo cultural, o PSD tem privilegiado o primeiro, nos últimos anos o CDS-PP tem pendido para o segundo.

À direita da direita, como afirma Riccardo Marchi no seu capítulo, e fora do enquadramento político mainstream, encontramos, nos dias de hoje e como expressão máxima, o PNR (Partido Nacional Renovador). Por forma a perceber o peso real desta direita enquanto desafiadora do status quo e alternativa à direita tradicional, foi analisada a evolução da extrema-direita em Portugal, desde a Revolução de Abril, em três dimensões: organizativa, eleitoral e programática. Resumidamente, é argumentado que o desafio antissistémico representado por esta direita tem diminuído em Portugal, quer na dimensão organizacional, quer na dimensão eleitoral. Isto é, desde 1974 tem diminuído o número efetivo de partidos e movimentos de extrema-direita e, consequentemente, o capital eleitoral destes. Todavia, a nível programático a situação da extrema-direita mantém-se inalterada, isto é, mantém-se pouco apelativa para um eleitorado mais radical ou potencialmente apoiante destas ideias.

Na sua relação com o estado, o mercado e a igreja, a direita portuguesa assume padrões e tendências diferenciados, dependendo do momento histórico. No que diz respeito ao seu posicionamento face à relação entre estado e mercado, a direita pode ser analisada através de três abordagens: conservadora, patrimonialista e liberal. Assim, e como é evidenciado por André Azevedo Alves, se os anos iniciais do Estado Novo se parecem facilmente enquadrar na abordagem conservadora, o período entre a entrada de Portugal na EFTA (European Free Trade Association), em 1961, e 1974 foi pautado por uma gradual e consistente liberalização. A Revolução dos Cravos e o período instável que lhe sucedeu parecem ter sido desastrosos, quer para a direita conservadora, quer para a liberal. Pelo contrário, foi a direita patrimonialista, devido à sua plasticidade, que melhor se adaptou aos novos tempos democráticos. Relativamente à relação entre direita, estado e igreja, o principal argumento de Luís Salgado de Matos é o de que, em Portugal e erradamente, não é assumida a existência de uma direita laica e de uma esquerda católica. Recorrendo a 
exemplos que remontam às revoltas liberais do século XIX, o autor mostra a existência de uma compatibilidade entre liberalismo e uma direita constitucionalista.

Culturalmente, com o 25 de Abril de 1974, assistimos ao surgimento de um fenómeno apelidado por António Araújo como "neoconservadorismo do gosto" / "neoconservadorismo do imaginário" (p. 15). Este, sendo primordialmente um fenómeno imagético e social, estava imbuído de um sentido político e ideológico. Concomitantemente, pela mão do jornal $O$ Indepentente e, posteriormente, da revista Kapa, surge uma direita urbana. Em oposição a uma direita tradicionalista, esta considerava-se intelectualmente superior, relativista nos costumes e liberal em termos económicos, fazendo a síntese entre o vanguardismo cultural e o saudosismo dos anos passados. Anos mais tarde, o advento da Internet e da blogosfera faz nascer uma nova direita, apelidada por Araújo "novíssima direita dos blogues" (p. 47). Esta, criada num meio pós-secular, é um produto do legado da sua antecessora e continua a opor-se a uma direita tradicional, que apelida acéfala, intolerante e ultramontana. Ora, a direita aqui descrita é aquela que, e usando a expressão de Alexandre Franco de Sá, tem contestado a "hegemonia da esquerda" (p. 142) no terreno cultural.

A opinião pública em Portugal, como o demonstram vários estudos desde 1974, localiza-se no centro do espetro político. A direita e a esquerda apresentam-se bastante equilibradas, embora haja uma ligeira vantagem da segunda face à primeira. Esta ideia de concentração do eleitorado português ao centro parece, inclusive, ter sido reforçada com a crise económico-financeira de 2008, como argumentam André Freire e Sofia Serra Silva. Ora, segundo estes dois autores, as maiores diferenças entre uma direita potencialmente autoritária e uma esquerda tendencialmente libertária centram-se em valores socioculturais, principalmente naqueles relacionados com questões religiosas. Para estes autores, esta fraca diferenciação entre esquerda e direita pode ser sintomática de uma menor qualidade democrática. A democracia é o reino da escolha e, logicamente, se as diferenças são poucas o eleitorado e a opinião pública perdem este poder.

Grandes crises tendem a ter impacto na configuração do tabuleiro político. Aquela porque passamos é, segundo Joaquim Aguiar, metade do problema. Isto é, a crise do início do século XXI é uma continuação daquela que, no final do século passado, se seguiu ao desmembramento da URSS. Esta crise conjunta remonta, por seu turno, à incapacidade, da esquerda e da direita, de, desde meados do século passado, alterarem os seus discursos e programas, adaptando-os às mutações sociais, económicas e demográficas - ocorridas. Segundo o autor, "o muro de Berlim caiu para os dois lados" (p. 383): esquerda e direita. A crise económica que deflagrou em 2008 evidenciou esse facto.

Este é um livro sobre as direitas na democracia portuguesa. No rescaldo de uma governação PSD/CDS-PP, essencialmente pautada pela presente crise económico-financeira. A sua leitura serve de ajuda à reflexão crítica sobre a vida portuguesa nos últimos anos. Entre cultura e opinião pública, economia e política, estado, mercado e igreja, elites e massas, este livro é um guia que nos introduz a "direita" nas suas diversas componentes. Todavia, sendo um livro sobre a direita, este é, indubitavelmente, também um livro sobre a esquerda. 
Mariana Carmo Duarte. Mestranda em Ciência Política, pelo ISCTE-IUL.

Licenciada em Ciência Política e Relações Internacionais, pela FCSH-UNL.

E-mail: marianacarmoduarte@gmail.com. 